\title{
A semântica argumentativa como base para análise de redações de vestibular
}

Cristiane Dall' Cortivo-Lebler Cristiano Sandim Paschoal ${ }^{* *}$

\section{Resumo}

Este artigo visa a analisar a abordagem e o desenvolvimento do tema, especialmente a construção de encadeamentos argumentativos e o uso de conectores, em redações produzidas por vestibulandos de uma universidade do Rio Grande do Sul. Fundamentou-se, para a devida análise, na Teoria da Argumentação na Língua em sua fase atual, a Teoria dos Blocos Semânticos, desenvolvida pelo semanticista Oswald Ducrot e por Marion Carel, cujo pensamento principal que a norteia é de que a linguagem é essencialmente argumentativa. Concluiu-se, a partir da análise de um corpus de 40 redações, que o uso de conectores linguísticos é primordial para uma boa qualidade textual e que é premente a necessidade de uma melhor aproximação entre teoria linguística e ensino para que se possibilite a alunos e a futuros vestibulandos construírem sentido no texto a partir do linguístico, bem como maior entendimento de todos os aspectos que circundam o universo textual.

Palavras-chave: Argumentação. Redação. Blocos semânticos.

\section{Introdução}

A aplicação de textos dissertativo-argumentativos como forma de avaliar a capacidade de expressão escrita tornou-se bastante utilizada no Brasil. Além do Exame Nacional do Ensino Médio (Enem), grande parte dos vestibulares e alguns concursos públicos incluem, em seus exames, propostas de textos dissertativos que serão submetidos à avaliação, como forma de classificação de seus candidatos.

Com o intuito de analisar como foram construídas as argumentações nas redações de vestibulandos, compilaram-se oitenta redações, elaboradas no vestibular de verão de uma universidade do

\footnotetext{
Doutora em Letras pela PUCRS. Professora do Programa de Pós-graduação em Letras e do Departamento de Letras da Universidade de Santa Cruz do Sul. E-mail: cristianedc@unisc.br

** Acadêmico do curso de Letras Espanhol da Universidade de Santa Cruz do Sul. Bolsista CNPq. E-mail: cristianopaschoal@mx2.unisc.br
}

Data de submissão: fev. 2018 - Data de aceite: jun. 2018 http://dx.doi.org/10.5335/rdes.v14i2.7959 
interior do Rio Grande do Sul, do ano de 2016. Dessas redações, estabeleceu-se um corpus de quarenta redações, com notas entre 2,0 e 10,0 pontos, que foram analisadas com base na Semântica Argumentativa, desenvolvida por Oswald Ducrot e Marion Carel.

É de conhecimento comum as dificuldades que os estudantes brasileiros apresentam em relação à produção textual, tanto no que se refere às construções linguísticas quanto ao conteúdo. No corpus analisado, por exemplo, apenas $10 \%$ das redações atingiram nota 10 ; $45 \%$ ficaram entre as médias 5,0 a 9,0 ; e $45 \%$ receberam notas entre 2,0 a 4,0 .

Nesse sentido, há, no Brasil, inúmeras pesquisas que investigam e discorrem sobre os diferentes aspectos linguísticos que circundam a produção textual e o fracasso dessa. Vale destacar o que afirma Rocco sobre sua pesquisa feita em produção textual de candidatos ao ensino superior, já em 1981:

A linguagem dos vestibulandos nestas redações produz apenas o discurso insípido e banal e, por que não dizer, o discurso desnecessário. Tê-lo escrito, como não o haver feito é a mesma coisa. Melhor seria que as folhas continuassem em branco (ROCCO, 1981, p.253 apud GRAEFF, 2006, p. 189).

Em vista disso, o objetivo desta pesquisa não será apenas o de analisar redações de vestibulandos, a fim de identificar as possibilidades de desenvolvimento de argumentações, mas, também, o de propiciar, mesmo que timidamente, um material teórico principalmente para professores de língua portuguesa cujo modelo geral de ensino, frequentemente, é pautado na gramática normativa - modelo que, pelos resultados que se observam em textos de vestibulandos, não está tendo resultados eficazes. Logo, tentar-se-á levar uma teoria linguística para o ensino, bem como para o fazer/ construir boas argumentações em textos de vestibulares.

Para tanto, o presente artigo se organizará da seguinte forma: em um primeiro momento, serão apresentadas as teorias linguísticas que embasam a pesquisa; em seguida, será feita a análise da proposta de redação do vestibular de verão/2016, da universidade em questão e, também, dos textos escritos pelos vestibulandos, ambas feitas a partir do recorte teórico da fase mais atual da Teoria da Argumentação na Língua, a Teoria dos Blocos Semânticos, proposta por Oswald Ducrot e por Marion Carel; por fim, as considerações finais acerca do que foi analisado e discutido.

\section{Revisitando Saussure}

Para entendermos a Teoria da Argumentação na Língua, proposta por Oswald Ducrot e colaboradores, faz-se necessário revisitarmos a linguística de Ferdinand de Saussure.

Segundo o professor genebrino (2002), para que possamos apreender a realidade, é preciso nomeá-la. Essa nomeação se dá por meio dos signos linguísticos, pois são eles que nos permitem falar de coisas presentes ou ausentes no ato 
da comunicação. Porém, de acordo com Saussure (2002), isso não significa ver a língua como sendo um sistema de representações que se sobrepõe à realidade, ou seja, a língua não equivale a nomenclaturas que sejam sobrepostas às coisas. Para que essas postulações fiquem mais claras, comecemos com uma das principais conceituações do estudioso em relação à língua: o signo linguístico.

Signo linguístico, segundo o teórico, é a união inseparável de um conceito (significado) e de uma imagem acústica (significante). Logo, poder-se-ia confundir signo com palavra. Entretanto, quando Saussure (2002) afirma que signo resulta da união conceito/imagem acústica, pressupõe que tudo aquilo que produzirmos com sentido se caracterizará como sendo signo. Segundo José Luiz Fiorin, “[...] as frases são signos, os textos são signos, qualquer produção humana dotada de sentido é um signo" (FIORIN, 2015, p. 60).

Partindo-se desse princípio, uma palavra como beber, por exemplo, é um signo, pois é formada pela imagem acústica /beber/ ligada, inseparavelmente, ao conceito de "ingerir líquido". Porém, esse signo é formado por outros signos: 0 radical/beb-/; o morfema -e, que indica que o verbo está na segunda conjugação; e o morfema -r, significando infinitivo. Isso nos leva a perceber que até os morfemas da língua podem ser signos, desde que tenham significante e significado. Mas o morfema $\mathbf{r}$ de beber seria o mesmo caso do $\mathbf{r}$, por exemplo, do signo "rua"? A resposta, segundo Saussure (2002), seria não, pois o /r/ de rua funciona apenas como fonema nessa palavra, não tendo significação isolado, ou seja, não se caracteriza como signo linguístico. Já o $\mathbf{r}$ de beber se caracteriza como tal porque carrega consigo uma conceituação, que é dada a partir da oposição -ndo de bebendo, que representa o gerúndio.

Atrelado a esse sistema de signos e oposições, encontra-se um conceito saussuriano que será determinante para a pesquisa de Ducrot (2006): o valor. Para Saussure (2002), valor seria o jogo de diferenças, oposições e negatividade que ocorrem no sistema da língua, ou seja, um signo só é o que é em relação àquilo que o outro não é. Por esse prisma, o linguista afirma:

[...] de um lado o conceito nos aparece como a contraparte da imagem auditiva no interior do signo, e, de outro, este mesmo signo, isto é, a relação que une seus dois elementos, é também, e de igual modo, a contraparte dos outros signos da língua. (...) A língua é um sistema em que os termos são solidários e o valor de um resulta tão somente da presença simultânea de outros (SAUSSURE, 2002, p. 133).

Isso nos leva a afirmar que o chamado valor linguístico do qual Saussure (2002) fala é o resultado da existência de outros signos e de suas relações que, por sua vez, ocorrerão em dois eixos: o associativo e o sintagmático.

Além da importância dessas dicotomias, segundo Saussure (2002), o signo linguístico apresenta uma característica que está intimamente ligada às noções de valor e de relação. Quando o linguista 
argumenta que o signo é arbitrário, significa que não há nada em seu significante que lembre o seu significado. Tomemos como exemplo a palavra "artigo": não há nada em seu significante que nos motive a pensar que o artigo significa trabalho acadêmico que apresenta resultados sucintos de uma pesquisa realizada de acordo com o método científico aceito por uma comunidade de pesquisadores. Entretanto, a partir do momento em que uma comunidade linguística universitária convenciona o conceito de artigo, seu significado se instaura socialmente. Vale aqui lembrar que, também, graças à relação sintagmática, consegue-se especificar o tipo de artigo a que se refere pois, a partir do eixo associativo, poder-se-ia substituir científico por opinião, jornalístico etc.

Além dos conceitos de signo, de valor e de relações sintagmáticas e associativas, o corte metodológico entre língua e fala, ainda que com algumas modificações, foi fundamental para que a Teoria da Argumentação na Língua definisse seus dados observáveis e seu construto teórico. Para Saussure (2002), a língua é definida como de natureza social e compartilhada, enquanto a fala é conceituada como individual e momentânea, sujeita às variações que lhes são constitutivas quando do uso da língua pelos sujeitos falantes. Assim, a fala e a língua ganham contornos de objeto real e de objeto do conhecimento, fundamentais para a delimitação dos dados e de como teoricamente esses dados podem ser explicados.
Admitimos que a teoria saussuriana sobre a linguagem é deveras mais ampla que o esboço aqui proposto. Entretanto, como nosso objetivo é apenas delimitar os conceitos que serviram como base epistemológica para a Teoria da Argumentação na Língua, consideramos suficiente a apresentação que realizamos até aqui. A seguir, elencamos alguns conceitos da Teoria da Argumentação na Língua (ANL) que foram fundamentais para o desenvolvimento desta pesquisa.

\section{A Teoria da Argumentação na Língua, de Oswald Ducrot}

A ANL é chamada por estudiosos da área como, por exemplo, Leci Barbisan (2007), de Semântica Argumentativa. Criada na França, na École des Hautes Études en Sciences Sociales de Paris por Oswald Ducrot e, inicialmente, Jean-Claude Anscombre, a ANL passou por diversas fases e mudanças, porém, todas as reformulações se mantiveram norteadas pelo principal pensamento de Ducrot, de que "[...] a linguagem é essencialmente argumentativa, visto não descrever diretamente a realidade, mas indiretamente, por meio dos aspectos subjetivos e intersubjetivos" (GRAEFF, 2006, p. 190).

Em outras palavras, o que o teórico quer dizer é que a argumentação está na língua, ou seja, o sentido está circunscrito ao linguístico, pois, para que seja explicado, não há a necessidade de recor- 
rer a elementos externos. Norteando-se, então, por esse pensamento, a ANL, em suas diferentes fases - Forma Standard (ANSCOMBRE; DUCROT, 1983), Teoria dos Topoi e Teoria Polifônica da Enunciação (DUCROT, 1987; DUCROT, 1990; DUCROT, 1999), Teoria dos Blocos Semânticos (CAREL, DUCROT, 2005; CAREL, DUCROT, 2008), e Teoria da Argumentação Polifônica (CAREL, 2011) -, buscou um alinhamento com o princípio saussuriano segundo o qual o significado de uma expressão está baseado nas relações que essa expressão mantém com outras de mesma natureza.

Na presente pesquisa, toma-se como base uma das fases mais atuais da Semântica Argumentativa - a Teoria dos Blocos Semânticos (TBS) -, sobre a qual versará a próxima seção.

\section{Teoria dos Blocos Semânticos}

Uma das versões mais atuais da Teoria da Argumentação na Língua, a Teoria dos Blocos Semânticos (TBS), tem como principal fundamento a concepção argumentativa da língua, cuja construção de sentido se dá por meio de encadeamentos argumentativos. Segundo a estudiosa Telisa Graeff, em seu artigo intitulado Teoria da Argumentação na Língua e Compreensão de Tema de Redação, "[...] o sentido de uma unidade linguística não é construído pelas coisas ou fatos que ela denota, nem pelos pensamentos ou crenças que exprime, mas pelos encadeamentos discursivos que evoca, a saber as argumentações" (GRAEFF, 2005, p. 115).
Marion Carel e Oswald Ducrot, no texto intitulado La semántica argumentativa. Una introducción a la teoria de los Bloques Semánticos (2005), propõem a existência de dois tipos de encadeamentos argumentativos que serão constituídos por um discurso do tipo X CON $\mathrm{Y}$, no qual CON será um conector. Esse conector, por sua vez, poderá ser de dois tipos:

A. Conector normativo: Trata-se de um conector em donc (DC), que, traduzido do francês para o português, significa portanto. Pode-se perceber que esse tipo de conector dá para a argumentação no discurso um sentido conclusivo/consecutivo.

B. Conector transgressivo: Trata-se de um conector em pourtant (PT), que, traduzido do francês para o português, significa mesmo assim ou no entanto. Logo, percebe-se, no encadeamento transgressivo, uma argumentação no discurso com sentido concessivo/opositivo.

Partindo, então, desse princípio, Carel e Ducrot (2005) afirmam que os enunciados projetados no discurso têm um sentido de "orientar para". Em outras palavras, o que a TBS atenta é para as palavras conectoras, que, vistas pela gramática normativa como sendo desprovidas de sentido, na verdade apresentam valor argumentativo. Conectores 
sintáticos, como portanto, entretanto, logo, mas, etc., condicionam linguistica e semanticamente uma sequência dentro do discurso.

A título de ilustração, observem-se enunciados como João usou chapéu na festa, portanto ficou elegante e João usou chapéu na festa, no entanto ficou elegante, os quais apresentam sentidos opostos, fruto da substituição de portanto por no entanto: no primeiro, a elegância é decorrente do uso do adereço; já no segundo, a elegância é algo contrário a esse uso. A escolha, no eixo associativo, por um ou por outro conector é crucial para a construção da argumentação. Assim, para esta pesquisa, será considerada primordial a existência de conectores nas redações analisadas, já que eles são os responsáveis pelo estabelecimento do sentido nos discursos.

\section{Saussure e Ducrot: aproximações}

Dizer que um linguista se inspirou em Saussure para criar uma teoria linguística é, de certa forma, uma redundância, uma vez que a linguística moderna nasce a partir dos estudos do professor genebrino.

Partindo das fundamentações de língua, fala, signo, valor e estrutura, diversos campos da linguística surgiram para reafirmá-los ou, até mesmo, para negá-los. Entre as muitas linguísticas que se ligam e/ou se opõem à vertente estruturalista, tem-se a Linguística da Enunciação, que tem como alguns de seus representantes Charles Bally, Roman Jakobson, Émile Benveniste, Mikhail Bakthin, Oswald Ducrot e Jacqueline Authier- Revuz, como nos apresentam Flores e Teixeira (2013).

Com o intuito de observar os efeitos de sentido produzidos por escolhas linguísticas de escritores em textos argumentativos, nosso estudo contemplará, principalmente, a teoria de Ducrot e, consequentemente, a de Saussure. Por quê? Vejamos o que diz o próprio Ducrot ao se perguntar sobre sua suposta fidelidade à Saussure:

Eu sou fiel à Saussure? Sob diversos ângulos, a resposta seria negativa, mas não no que se refere à noção de valor, que eu sempre quis colocar como sendo a norteadora do meu trabalho em semântica: cada vez que eu falava de uma entidade, sempre tentava caracterizá-la pelo valor que permitia declarar essa entidade [...] (DUCROT, 2006, p.153) (tradução nossa). ${ }^{1}$

Como se pode ver, no texto intitulado La Sémantique Argumentative peut-elle se réclamer de Saussure?, de Oswald Ducrot, o autor declara que a postulação de Saussure que mais o norteia é o conceito de valor linguístico. Ducrot (2006), ao fazer essa afirmação, economizou boa parte das explicações que se fariam necessárias, uma vez que, associada à noção de valor, está a noção de língua, que, por sua vez, se atrela à noção de sistema, o qual está ligado à noção de estrutura, que se vincula às relações.

Primeiramente, quando Saussure (2002) define que um signo linguístico é aquilo que outro não é, significa, para o linguista, que não há a necessidade de 
observar um elemento extralinguístico para deduzirmos seu sentido, uma vez que esse será determinado pela/na língua por oposição. Logo, quando Ducrot (2009) afirma que a língua é argumentativa e que se configura por meio de frases em encadeamentos argumentativos, significa que tais frases só existem a partir da existência de outras, pois "uma entidade linguística [...] não poderá definir-se independentemente de seu emprego em um diálogo. [...] $\mathrm{O}$ enunciado se definirá então pelas possibilidades de resposta que abre e por aquelas que fecha. [...] sua realidade não se localiza nele, mas fora dele - nos outros enunciados" (DUCROT, 2009b, p. 11-12).

Além dessa aproximação, é importante que atentemos para o fato de Ducrot (2009a) visualizar o discurso como sendo dotado de sentido, pois as escolhas linguísticas do locutor, segundo ele, argumentam. Porém, nos perguntemos: tais escolhas estarão onde? A resposta para essa pergunta será o eixo associativo, proposto por Saussure (2002), pois esse eixo estará presente no sistema da língua e seu uso e apropriação será de caráter individual. É o eixo associativo que definirá a natureza do encadeamento argumentativo, conforme os segmentos que se relacionam e o conector $(\mathrm{CON})$ escolhido.

Além dessas escolhas linguísticas no discurso, Ducrot (1990, 2009b) afirma, no escopo da Teoria da Argumentação na Língua (TAL), que a língua é intersubjetiva e, por isso, o locutor leva o seu alocutário a dar-lhe uma resposta. Essa resposta, a qual o locutor espera, fica à mercê daquilo que foi dito/escrito ante- riormente. Essa relação configurar-se-á no eixo sintagmático, porém será dada a partir da enunciação, pois é por meio de um ato enunciativo que o sujeito constrói sentidos. Como? Argumentando e, segundo Ducrot (2009a), argumentando por intermédio de enunciados do tipo $\mathrm{X}$ CON Y. Abaixo, apresenta-se uma figura que ilustra as relações entre Saussure e Ducrot, mediadas pela enunciação:

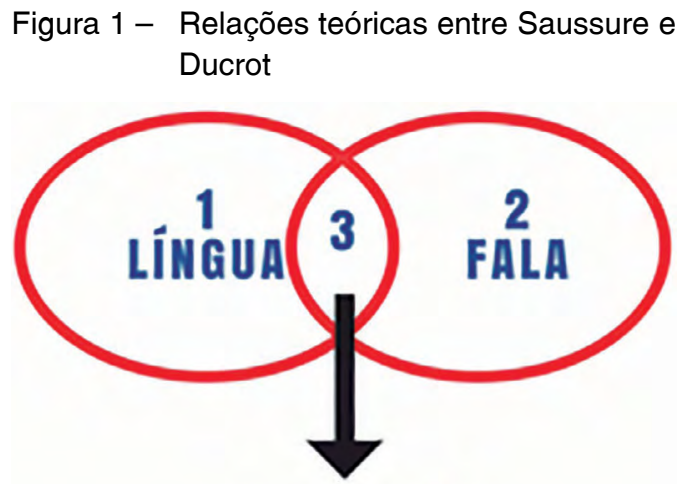

\section{ENUNGIAĢão}

Fonte: os autores.

A partir da Figura 1, podemos concluir que:

1. Refere-se ao sistema língua que, segundo Saussure (2002), é composta por signos que se relacionam, em associações e sintagmas, atribuindo-lhes valor;

2. Refere-se ao uso da língua;

3. Instância de mediação entre a língua e a fala, resultando, assim, na transformação da língua em discurso. Esse emprego da língua, segundo Ducrot, ocorrerá pela argumentação, num enunciado do tipo X CON Y. 


\section{Metodologia}

A presente pesquisa, conforme afirmado na introdução, apresenta como objetivo a análise do desenvolvimento do tema, especialmente a construção de encadeamentos argumentativos e o uso de conectores, em redações de vestibular de uma universidade do interior do Rio Grande do Sul. Para isso, foram selecionadas, de um universo de oitenta textos que compõem o corpus da pesquisa, quarenta redações com notas entre 2,0 e 10 pontos, atribuídas pela banca examinadora do vestibular, sem especificação do curso de graduação escolhido pelo candidato.

Os procedimentos de análise incluíram: a) a análise da proposta de redação, com o objetivo de identificar as possibilidades de encadeamento argumentativo passíveis de serem desenvolvidos pelos vestibulandos; $b$ ) estratificação das redações de acordo com a nota atribuída pela banca; c) identificação do encadeamento argumentativo desenvolvido na redação e sua correspondência ou não com as possibilidades elencadas a partir da análise da proposta; d) identificação da quantidade e da variedade de conectores presentes nos textos analisados.

\section{Análise dos dados}

A seguir, apresenta-se a análise da proposta de redação do vestibular com base em Dall' Cortivo-Lebler e Gomes (2017) e, após, desenvolve-se a análise do corpus da pesquisa. Neste artigo, assume-se, metodologicamente, que os encadeamentos argumentativos são paráfrases dos enunciados, enquanto os aspectos argumentativos são representações abstratas desses encadeamentos. Assim, entende-se que as redações, bem como o tema da proposta, materializam - ou apresentam possibilidades de materialização de - determinados sentidos cuja estrutura se assenta sobre os aspectos argumentativos. Cada redação, portanto, poderá desenvolver um aspecto daqueles possibilitados pelos textos motivadores da proposta ou, em caso de não o fazer, será enquadrada na rubrica "fuga ao tema".

\section{Análise da proposta de redação}

As propostas de redação do vestibular da universidade em questão foram três, apresentadas na seguinte ordem: 0 TEMA 1 propõe ao aluno o enfoque da relação entre política e politicalha; o TEMA 2 propõe a abordagem das estratégias de alienação da sociedade contemporânea; TEMA 3 propõe a argumentação sobre a solidariedade enquanto bem social. Optou-se, para a análise da proposta de redação, o tema de número 3 , pelo volume de redações produzidas pelos vestibulandos, o que possibilitou a constituição do corpus com notas dentro do espectro estipulado - 2,0 a 10,0 pontos. Na Figura 2, apresenta-se a reprodução da proposta de redação: 
Figura 2 - Proposta de redação.

\section{TEMA 3}

Na França pai ganha 350 dias de férias para cuidar de filha com câncer.

"Usei todos os meus dias de férias em exames médicos e sessões quimioterápicas", contou ele ao jomal local Le Réveilde Neufchâtel.

Mas a solidariedade de seus colegas de trabalho fez com que a situaçào de Dupré mudasse radicalmente. Eles decidiram doar suas férias para que Dupré pudesse cuidar de sua filha.

Com isso, ele passou a ter direito a nada menos do que 350 dias de férias. (BBC Brasil outubro 2015)

Quando a ganância parece tomar conta das pessoas, exemplos de solidariedade dão um novo sopro de esperança. Aborde, num texto argumentativo, a solidariedade enquanto um bem social e como essa característica pode representar a dimensão humanitária necessária para a construção de um mundo melhor.

Fonte: Prova de redação aplicada pela instituição.

Pode-se observar que a proposta de tema 3 apresenta aos candidatos, primeiramente, uma notícia que foi divulgada pela BBC Brasil. Após isso, a proposta apresenta uma estrutura linguística iniciada pelo operador argumentativo MAS. Nesse sentido, lembremos o que afirma Telisa Graeff em seu artigo: "conforme Ducrot e Anscombre, uma estrutura como A MAS B apresenta A e B como opostos, sendo que o locutor de A MAS B prefere B em detrimento de A" (2005, p.118).

Observa-se que, na proposta de redação, o conector MAS não está opondo ideias contrárias, porém, o simples fato de esse articulador dar a ideia de NO ENTANTO, espera-se que o candidato levante possibilidades acerca dessa oposição. Nesse caso, poder-se-ia chegar às seguintes questões: caso Dupré não recebesse 350 dias de férias, o que aconteceria? Qual foi o impacto da atitude de seus colegas em sua vida?

Além disso, pode-se dizer que os dois primeiros textos motivadores da proposta contemplam, segundo a TBS, quatro possibilidades de continuação, ou de aspectos normativos (X DC Y), em que DC será portanto ou outras expressões normativas. São eles:

Aspecto argumentativo A: SOLIDARIEDADE DC BEM SOCIAL Aspecto argumentativo B: SER SOLIDÁRIO DC CONSTRUIR UM MUNDO MELHOR Aspecto argumentativo C: SOLIDARIEDADE ENQUANTO BEM SOCIAL DC SER SOLIDÁRIO Aspecto argumentativo D: NÃO SER SOLIDÁRIO DC NÃO CONSTRUIR UM MUNDO MELHOR

Faz-se necessário observar que a proposta de redação apresenta mais possibilidades de aspectos normativos, entretanto não se espera um posicionamento contrário à proposta. Por isso, aspectos do tipo SOLIDARIEDADE DC NÃO BEM SOCIAL, SER SOLIDÁRIO
DC NÃO CONSTRUIR UM MUNDO MELHOR OU NÃO SER SOLIDÁRIO DC CONSTRUIR UM MUNDO MELHOR, iriam de encontro àquilo que prega a própria proposta, configurando-se, dessa forma, como fuga ao tema. 
Assim, se a língua é intersubjetiva e o locutor, ao se enunciar, obriga seu interlocutor a dar-lhe uma resposta que é uma continuação do seu discurso, então, podemos entender que as redações são continuidades do discurso contido no enunciado da proposta, tendo como objetivo, portanto, preencher uma lacuna desse discurso. A obediência à orientação semântica da proposta é que configura o esperado, sendo o contrário - a desobediência - considerado uma inadequação quanto ao desenvolvimento do tema.

Quanto à possibilidade de aspecto transgressivo, quando o enunciado da proposta afirma que se vive em tempos em que a ganância tomou conta das pessoas, tendo-se, com exemplos de atitudes solidárias, um sopro de esperança, poder-se-á ter a possibilidade de aspecto transgressivo X PT Y. Logo:

Aspecto argumentativo E: GANÂNCIA PT EXEMPLO DE SOLIDARIEDADE DÁ SOPRO DE ESPERANÇA

Após a identificação dos aspectos argumentativos passíveis de ser desenvolvidos a respeito do tema da redação, selecionou-se e numerou-se um corpus de quarenta, das oitenta redações produzidas. Analisaram-se textos com notas entre $2.0 \mathrm{e}$ 10.0 pontos - de 4 a 5 redações para cada faixa de pontuação - a fim de descrever as diferentes argumentações construídas acerca do tema proposto, identificando quais delas colaboraram para um bom desempenho na prova de redação.

\section{Análise das redações}

É necessário salientarmos que qualidades como legibilidade do texto, respeito à tipologia textual, mecanismos linguísticos (coesão e coerência), domínio da variedade padrão e defesa do ponto de vista com autoria foram consideráveis para a obtenção da nota na redação. Entretanto, na presente pesquisa, observou-se apenas a qualidade argumentativa e abordagem temática pelo desenvolvimento (ou não) de aspectos normativos e transgressivos e, mais ainda, como esse desenvolvimento contribuiu para a construção de sentido.

A seguir, encontra-se a Tabela 1, composta por quatro colunas, que sintetiza parte da análise: na primeira coluna, encontra-se a identificação da redação analisada; na segunda, descreve-se o aspecto argumentativo desenvolvido pelo candidato de acordo com as possibilidades elencadas na análise da proposta de redação (vide seção 6.1), ou, caso o candidato tenha desenvolvido um aspecto não previsto pela proposta, faz-se o registro como "fuga ao tema"; na terceira coluna, apresenta-se o número de conectores utilizados pelo candidato em seu texto; e, na quinta coluna, apresenta-se a nota atribuída à redação pela banca examinadora do vestibular. Faz-se importante esclarecer que, na tabela, enumeraram-se e distribuíram-se as redações conforme as médias obtidas, em ordem crescente. $\mathrm{O}$ fato de as médias serem mais significativas conforme o maior número de conectores é um fator relevante, já que a boa utilização de conectores traz ao texto mais argumentatividade e, em consequência, explicita as relações de sentido. 
Tabela 1 - Síntese da análise do corpus

\begin{tabular}{|c|c|c|c|}
\hline $\begin{array}{l}\text { № da } \\
\text { redação }\end{array}$ & $\begin{array}{l}\text { Aspecto Argumentativo de acordo } \\
\text { com a seção } 6.1\end{array}$ & $\begin{array}{l}\text { Número de conectores } \\
\text { apresentados }\end{array}$ & $\begin{array}{l}\text { Média } \\
\text { Final }\end{array}$ \\
\hline 1 & Aspecto A & sem conectores & 2,5 \\
\hline 2 & Fuga ao tema & sem conectores & 2,5 \\
\hline 3 & Fuga ao tema & sem conectores & 2,5 \\
\hline 4 & Aspecto D & sem conectores & 2,5 \\
\hline 5 & Aspecto A & sem conectores & 2,0 \\
\hline 6 & Aspecto B & sem conectores & 2,0 \\
\hline 7 & Aspecto B & sem conectores & 2,0 \\
\hline 8 & Aspecto B & 1 conector & 3,0 \\
\hline 9 & Aspecto A & sem conectores & 3,0 \\
\hline 10 & Aspecto D & sem conectores & 3,0 \\
\hline 11 & Aspecto D & sem conectores & 3,5 \\
\hline 12 & Aspecto A & sem conectores & 3,5 \\
\hline 13 & Aspecto D & 1 conector & 4,0 \\
\hline 14 & Aspecto B & 3 conectores & 4,0 \\
\hline 15 & Aspecto B & 3 conectores & 4,5 \\
\hline 16 & Aspecto $\mathrm{E}$ & 2 conectores & 4,5 \\
\hline 17 & Aspecto A & 1 conector & 4,5 \\
\hline 18 & Aspecto D & sem conectores & 5,0 \\
\hline 19 & Aspecto $\mathrm{E}$ & 2 conectores & 5,75 \\
\hline 20 & Aspecto A & 4 conectores & 5,25 \\
\hline 21 & Aspecto D & 1 conector & 5,5 \\
\hline 22 & Aspecto A & 1 conector & 5,0 \\
\hline 23 & Aspecto A & 1 conector & 6,0 \\
\hline 24 & Aspecto B & 3 conectores & 6,0 \\
\hline 25 & Aspecto C & 3 conectores & 6,5 \\
\hline 26 & Aspecto A & 2 conectores & 6,5 \\
\hline 27 & Aspecto C & 1 conector & 7,0 \\
\hline 28 & Aspecto D & 3 conectores & 8,5 \\
\hline 29 & Aspecto A & 4 conectores & 8,5 \\
\hline 30 & Aspecto A & 3 conectores & 8,5 \\
\hline 31 & Aspecto D & 4 conectores & 9,0 \\
\hline 32 & Aspecto A & 4 conectores & 9,0 \\
\hline 33 & Aspecto B & 4 conectores & 9,0 \\
\hline 34 & Aspecto E & 2 conectores & 9,0 \\
\hline 35 & Aspecto A & 7 conectores & 9,0 \\
\hline 36 & Aspecto A & 3 conectores & 9,0 \\
\hline 37 & Aspecto A & 4 conectores & 10 \\
\hline 38 & Aspecto B & 5 conectores & 10 \\
\hline 39 & Aspecto A & 3 conectores & 10 \\
\hline 40 & Aspecto C & 5 conectores & 10 \\
\hline
\end{tabular}

Fonte: autores. 
Nota-se, na tabela apresentada, que 15 redações optaram pelo aspecto argumentativo SOLIDARIEDADE DC BEM SOCIAL. Esse número de redações corresponde a $37,5 \%$ do corpus total (40 redações). Nas redações que desenvolveram esse aspecto, constatou-se que:

As redações de números 1, 5, 9 e 12 obtiveram, respectivamente, as notas 2,$5 ; 2,0 ; 3,0$ e 3,5 , que são médias consideradas muito baixas. Provavelmente, um dos motivos de maior relevância para isso é o fato de essas redações, apesar de desenvolverem a ideia do aspecto normativo $\mathrm{A}$, não apresentaram explicitamente, em seu desenvolvimento, nenhum conector; ou seja, nesses textos, as relações normativas de sentido explicitadas pelos conectores configuraram-se inexistentes.

As redações de números 17, 20, 22,23 e 26 obtiveram, respectivamente, as notas 4,$5 ; 5,25 ; 5,0 ; 6,0$ e 6,5. Pode-se dizer que, apesar de essas médias não serem tão baixas, não se pode considerá-las boas, tendo em vista o ponto de corte de alguns dos cursos oferecidos pela universidade. A redação de número 17, apesar de optar por um encadeamento normativo, não o representou linguisticamente. Entretanto, em uma de suas orações, utilizou a conjunção mas para a oposição de ideias, configurando, assim, um aspecto transgressivo:

(linha 02 a linha 05)

"Sonhamos todos os dias com um mundo bom, sem guerra, sem crimes, sem mortes, um mundo em que a aparência não esteja acima do caráter, esse é o lugar onde todos querem viver, MAS poucos ajudam a construir."

- As redações de números 20 e 22 utilizaram, cada uma, um conector normativo. A primeira utilizou o pois, e a segunda utilizou o então. Nas redações representadas pelo número 23 e 26, identificou-se a utilização de portanto. Porém, na redação de número 26 , observou-se, na conclusão do texto, que o candidato(a) optou por iniciar o parágrafo com a expressão conclui-se que, a fim de dar a ideia consecutiva a tudo que havia sido discutido anteriormente no texto:

(linha 20 à linha 25)

"CONCLUI-SE que está mais do que na hora de as pessoas perceberem que todos caminham juntos e que ser solidário ajuda essa caminhada a ser MELHOR. Talvez a chave para a criação de uma sociedade MELHOR seja, como diz um autor "fazer bem sem olhar a quem". 
- As redações de números 29 e 30 obtiveram a média 8,5 , apresentando 3 conectores de natureza normativa: assim, por isso e portanto. As redações de números 32,35 e 36 apresentaram média 9,0 - considerada muito boa - e cada uma delas utilizou 4 conectores normativos, variando entre assim, por isso, portanto, consoante a isso e logo, explicitando, de modo muito claro, as relações semânticas no texto. Já as redações de números 37 e 39 , além de apresentarem tais características, continham enunciados transgressivos, representados, em ambos, pelo conector entretanto. Para fins de exemplificação, segue a introdução da redação 37 , cujo aspecto argumentativo desenvolvido é SOLIDARIEDADE DC BEM SOCIAL, o qual aparece no último enunciado do excerto: (linha 01 à linha 06)

"O imediatismo e o ápice tecnológico vivenciados nos últimos anos têm esfriado e anestesiado nossos relacionamentos interpessoais. No intuito de otimizar o uso do tempo, mergulhamos no mundo virtual que muito nos auxilia. ENTRETANTO, nos tornamos gradativamente egoístas. NESSE SENTIDO, a solidariedade é um bem social que deve ser recuperado..."
A estratégia argumentativa utilizada pelo candidato exemplifica o que afirma Ducrot (2009a, p. 24), para quem a concessão é uma importante ferramenta argumentativa, já que "constitui [...] uma imagem favorável, a de um homem que aceita a discussão, que não procura impor-se brutalmente" e, assim, melhora o seu ethos. A estratégia concessiva apresenta já argumento e contra-argumento, levando em consideração, de certa forma, outros pontos de vista a respeito dos quais o locutor opta por posicionar-se de modo opositivo.

Em relação à possibilidade do aspecto normativo B, que corresponde a SER SOLIDÁRIO DC CONSTRUIR UM MUNDO MELHOR, encontramos um número de redações correspondente a $17,5 \%$ ( 7 redações) do corpus total. Nesses textos, observou-se que:

Nas redações de números 6 e 7 , que obtiveram a média 2,0 , houve a tentativa de desenvolver o encadeamento normativo supra citado, porém sem a utilização de conectores conclusivos/consecutivos, prejudicando, assim, a explicitação do sentido. A redação de número 8 , que também obteve uma média baixa $-3,0$ pontos -, utilizou apenas 1 conector normativo (portanto), porém, ao fazê-lo, acabou contrastando o conceito de egoísmo, abordado no $3^{o}$ parágrafo, com o conceito de ganância, abordado no $4^{\underline{0}}$ parágrafo. Essa confusão de conceitos atrelada ao uso indevido 
do conector prejudicou a argumentação. Além disso, ocorreu um erro ortográfico no conector. Todavia, tal erro (a troca da letra t pelo d), acabou resultando num vocábulo existente na língua (portando, do verbo portar) que, apesar de estranho, pois ninguém porta a ganância, poderia estar no lugar com sentido de praticar, uma vez que não foi separado por vírgula, como, em geral, são os conectores. Esse exemplo ilustra que a mudança de significante, no eixo associativo, resulta numa mudança de significado:

(linha 14 à linha 21)

"Se você não quer mais esta roupa dê para quem precisa, ela vai ficar bem feliz. Quando estiver caminhando na rua e vir um mendigo, não dê gargalhadas, vai lá e alcance um pão a ele. Tudo que fizermos de bom às pessoas, não vai nos fazer falta.

PORTANDO (sic) a ganância não nos leva a lugar nenhum, ao contrário, vai fazer com que as pessoas fiquem com raiva de nós...”

- As redações de números 14,15 e 24 , que obtiveram, respectivamente, as notas 4,0, 4,5 e 6,0, apesar de desenvolverem o aspecto normativo SER SOLIDÁRIO DC CONSTRUIR UM MUNDO MELHOR por meio de um bom posicionamento, pouco fizeram uso de conectores - verificou-se a utilização de apenas 1 em cada um dos textos. Nesse sentido, pode-se dizer que a ausência de nexos normativos em posições textuais nas quais deveriam estar presentes dá ao texto a ideia de algo inacabado, ou melhor, sente-se que as ideias defendidas no texto parecem estar inacabadas.

- Em relação às redações de números 33 e 38, que obtiveram, respectivamente, as médias $9,0 \mathrm{e}$ 10 , observou-se o bom desenvolvimento desse encadeamento por meio da utilização de 4 conectores normativos: portanto, assim - 2 vezes - e logo.

As redações que optaram pelo aspecto argumentativo $\mathrm{C}$ correspondem a 7,5\% (3 redações) do corpus total. Trata-se de um aspecto normativo, SOLIDARIEDADE ENQUANTO BEM SOCIAL DC SER SOLIDÁRIO, cujo próprio bloco semântico anula a possibilidade de inexistência de conectores, pois ele é uma combinação dos aspectos A e B. Dito isso, constatou-se que:

- Na observação da redação de número 25 , pôde-se detectar uma tentativa de encadeamento transgressivo na introdução. Porém, tal tentativa foi mal sucedida e, em decorrência disso, desencadeou-se um aspecto argumentati- 
vo não autorizado pela proposta: NEG SER SOLIDÁRIO PT NEG AJUDAR O PRÓXIMO.

(linha 01 à linha 04)

"Atualmente, em meio ao constante desejo de possuir mais bens materiais, as pessoas tornaram-se cada vez mais egoístas. No entanto, há ainda estudos realizados em diversos países que o desejo de ajudar o próximo morreu.".

- A redação de número 27 , cuja média foi 7,0 , apresentou legibilidade, domínio da norma padrão e respeito à tipologia textual. Porém, a inexistência de entrelaçamento linguístico entre os parágrafos, que se dá geralmente pelo uso de conectores normativos e/ou transgressivos, impossibilitou ao texto a ideia de progressão argumentativa, uma vez que os parágrafos poderiam ter sido lidos isoladamente ou em qualquer ordem. Já a redação de número 40, que obteve a média 10, apresentou um bom entrelaçamento linguístico e o uso de cinco conectores, sendo três normativos, configurados em portanto, por isso, assim e logo, e um transgressivo, configurado em entretanto.

Quanto ao último aspecto normativo possível NÃO SER SOLIDÁRIO DC NÃO CONSTRUIR UM MUNDO MELHOR, houve oito redações que optaram por esse, equivalendo a $20 \%$ do corpus total. Trata-se de um aspecto cujo bloco semântico se configura por meio da negação de ambos os segmentos do aspecto B, sendo-lhe, portanto, recíproco. Observou-se que:

- Nas redações de números 04, $10,11,13$ e 18 , que obtiveram, respectivamente, as médias 2,5 ; 3,$0 ; 3,5 ; 4,0$ e 5,0 , constatou-se a inexistência de conectores normativos. Já a redação de número 21 apresentou apenas 1 conector entre enunciados, porém entre parágrafos não houve ocorrência.

- As redações de números 28 e 31, que obtiveram, respectivamente, as médias 8,5 e 9,0 , desenvolveram muito bem o aspecto normativo $\mathrm{D}$. A redação de número 28 apresentou 3 conectores normativos, configurados em portanto, dessa forma e nesse sentido, bem como iniciou o terceiro parágrafo com a locução conectiva além disso a fim de intensificar a afirmativa anteriormente feita, de que sem sermos solidários nunca construiríamos um mundo melhor. Já a redação de número 31 apresentou 6 conectores normativos (portanto, desse modo, assim, devido a isso, logo e bem como), além de usar construções sintáticas transgressivas com os conectores entretanto e porém. 
A exemplo, o último parágrafo do texto 28 mostra um bom entrelaçamento entre enunciados, através do uso de conectores normativos:

"PORTANTO, na sociedade contemporânea, a solidariedade é o bem necessário para a construção de um mundo mais pacífico, justo e digno de se viver. DESSA FORMA, os conflitos existentes entre as diferentes culturas serão amenizados, de maneira a proporcionar um futuro melhor ás próximas gerações. POR FIM, estando de braços abertos, como o Cristo Redentor, será possível garantir uma vida repleta de amor, paz e esperança a todas populações."

Em relação ao único encadeamento transgressivo permitido pela proposta, GANÂNCIA PT EXEMPLO DE SOLIDARIEDADE DÃO SOPRO DE ESPERANÇA, encontraram-se quatro redações que o desenvolveram, representando $10 \%$ do corpus total. Dentre essas redações, duas, de número 16 e 19, obtiveram, respectivamente, as médias 4,5 e 5,75, apresentando, cada uma, duas vezes o conector transgressivo entretanto. As redações de números 34 e 38 obtiveram, respectivamente, as médias 9,0 e 10. A primeira apresentou dois conectores, sendo um normativo (assim) e um transgressivo (porém) ligando parágrafos. A última, por sua vez, apresentou 5 conectores, três deles ligando enunciados, representados por nesse sentido, entretanto e além disso; e dois deles fazendo o encadeamento entre parágrafos, representados por portanto e, outra vez, além disso.

Ainda, na seção de análise de redações, faz-se pertinente trazer alguns apontamentos do corpus total (40 redações) analisado:

- As redações de números 2 e 3 , cujas notas foram 2,5 , não apresentaram nenhum aspecto normativo possível e, consequentemente, fugiram ao tema. A redação de número 2 abordou a temática do câncer, apresentada na proposta de redação, porém o/a candidata(o) não atentou para o fato de que a proposta cita o câncer, mas centraliza a atenção para a solidariedade dos colegas de trabalho de Dupré, que doaram suas próprias férias para o pai poder cuidar de sua filha com câncer. Já a redação de número 3 abordou o conceito de ganância, também citado na proposta, porém não a contrastou com exemplos de solidariedade (temática central).

Doze redações, representando $30 \%$ do total do corpus, não obtiveram nenhuma ocorrência de conectores linguísticos, apesar de desenvolverem as ideias de algum aspecto argumentativo. 
- Sete redações, representando $17,5 \%$ do total do corpus, apresentaram apenas um conector linguístico, número este considerado baixo em se tratando de texto argumentativo que, por sua natureza, exige elementos coesivos dessa natureza.

- Atrelado à baixa incidência de nexos semânticos, percebeu-se certa limitação na escolha lexical dos textos escritos. Observou-se, nos textos que apresentaram mais de um conector, certa dificuldade de substituição de nexos linguísticos que tivessem um valor semântico semelhante. Abaixo, será explicitado esse fato, utilizando quatro enunciados, retirados do texto de número 20 :

Linha 7: "Ser solidário é um dos atos mais dignos do ser humano, POIS demonstra seu lado racional e emocional em conjunto, ajudando o próximo como a si mesmo" Linha 10: "Com pequenos atos diários, podemos transformar 0 mundo em um local agradável e bom desse viver, POIS assim, todos teremos as mesmas oportunidades, POIS nos sentiremos igual a todas as pessoas"

Linha 16: "Ser solidário depende somente da própria pessoa, POIS ninguém pode obrigar alguém a ser solidário no lugar da pessoa"
Linha 20: "Tornar o mundo um lugar mais humano, é um dever e direito de todos que nele habitam, POIS fará tanto um bem pessoal, como conjunto, onde todos se sentirão melhor."

A partir dos quatro enunciados retirados do texto de número 20, pôde-se notar (não somente nesse texto, mas também em outros) certa dificuldade de substituição no eixo paradigmático, citada anteriormente. Vejamos como se configurariam esses enunciados caso a substituição fosse feita, lembrando que uma delas pode se manter com o conector pois:

Linha 7: "Ser solidário é um dos atos mais dignos do ser humano, uma vez que demonstra seu lado racional..."

Linha 10: “...podemos transformar o mundo em um local agradável e bom de se viver, sendo assim..." Linha 16: "Ser solidário depende somente da própria pessoa, portanto ninguém pode..."

Linha 20: “...é um dever e um direito de todos que nele habitam, pois fará tanto...”

- Verificou-se, também, na análise da maioria dos textos, certa circularidade textual, ou seja, vários enunciados repetindo a mesma ideia por meio de paráfrases. Acompanhemos, abaixo, 
um exemplo disso, retirado da redação de número 21 :

Linha 20: “... o ser humano realmente racional..."

Linha 22: “...pela lógica o ser humano é realmente racional...”

- Ainda, pôde-se notar, na tabela acima apresentada, a preferência por aspectos normativos, especialmente pelo aspecto $\mathrm{A}$, que estava explícito na proposta e foi escolhido por $37,5 \%$ dos candidatos. Entendemos que isso se deve ao fato de a proposta de redação não permitir o desenvolvimento de muitos aspectos transgressivos (havia somente uma possibilidade). Nesse sentido, porém, vale observar que, mesmo que um texto tenha em seu desenvolvimento principal um aspecto normativo, não significa que em seu dissertar não possa haver construções de caráter transgressivo com seus respectivos conectores. Talvez, o fato de o pensamento normativo estar muito próximo do senso comum possa, de alguma forma, inibir a transgressão de ideias.

\section{Considerações finais}

Optou-se, neste artigo, chamar o último item de considerações finais e não de conclusão, principalmente pelo fato de, na análise das redações, levantarem-se muitos questionamentos a respeito do universo textual. $\mathrm{O}$ primeiro deles nos remete às palavras de Ducrot (2009), para quem todo discurso é argumentativo, já que a argumentação está inscrita na língua, sendo-lhe, portanto, constitutiva. Porém, contatou-se, na observação dos dados quantitativos, que a baixa qualidade textual de vestibulandos está intimamente ligada à dificuldade lexical para a seleção adequada de conectores normativos e/ou transgressivos, bem como a relação semântica que esses termos estabelecem em enunciados do tipo X CON Y.

Relacionado a isso, vale lembrar as palavras de Rocco (1981), citadas, inicialmente, neste estudo, as quais afirmam que teria sido melhor que as redações por ele analisadas não tivessem sido escritas. Entretanto, neste estudo, transferindo a inspiração teórica de Saussure no que diz respeito ao valor linguístico, cujo constructo teórico está baseado na Teoria da Alteridade, de Platão, colocou-se no lugar do outro, ou seja, dos candidatos escritores e, por fim, chegou-se à seguinte conclusão: dizer, em tempos de ameaças à escrita, que o que foi escrito seria melhor não ter sido feito é uma censura à expressão individual.

Assumindo, então, esse posicionamento, o presente artigo verificou que a maioria dos textos contemplados tentaram "dar seu recado", porém não o fizeram plenamente. Ora, se alguém disser ou escrever, por exemplo, a seguinte afirmação: Cassandra é boa professora, 
não se pode inferir, ao certo, o que esse alguém pretende ao dizer/escrever isso até o momento em que esse alguém construa, de fato, um encadeamento que dê sentido unitário a esta construção: Passei de ano PORTANTO Cassandra é boa professora / Neste semestre entendi toda matéria PORTANTO Cassandra é boa professora/ Cassandra é boa professora MESMO ASSIM fui mal na prova, e assim por diante.

Argumentar é, pois, dar sentido ao que está sendo dito/escrito, anterior e posteriormente, em que segmentos A e B são relacionados semanticamente. Logo, surge nossa primeira urgência em relação à escrita textual: faz-se necessária uma aproximação entre teorias linguísticas e ensino de língua portuguesa. Ao invés de centralizar o ensino de língua na categorização, seria interessante aproximá-lo das teorias linguísticas, dando ao aluno a capacidade de se comunicar, e bem, pelo meio linguístico. Atenta-se aqui para o fato de que não se está querendo dizer que o aluno não sabe se comunicar. Entretanto, na argumentação linguística, configurada, principalmente, na escrita, há uma relação entre locutor e texto; o outro, o tu, o leitor não está presente. Então como é possível fazer-se entender por meio escrito? A resposta pode ser dada, possivelmente, por meio dessa aproximação, cuja ideia o presente artigo tanto preconiza. E, certamente, uma das teorias que aqui se clama para o ensino de produção escrita é a Semântica Argumentativa.

\section{La Semántica Argumentativa como base para el análisis de redacciones de vestibular}

\section{Resumen}

Este artículo visa analizar el abordaje y el desarrollo del tema en redacciones de inscriptos en el proceso selectivo de una universidad del Rio Grande do Sul. Se fundamentó, para el debido análisis, en la Teoría de la Argumentación en la Lengua, desarrollada por el semanticista Oswald Ducrot y sus colaboradores, cuyo pensamiento principal la nortea es de que el lenguaje es esencialmente argumentativo. Se concluyó, a partir que del análisis de un corpus de 40 redacciones, la necesidad de una mejor aproximación entre teoría lingüística y enseñanza para que se posibilite a alumnos y futuros universitarios construir sentido en el texto a partir del lingüístico, bien como mayor entendimiento de todos los aspectos que circundan el universo textual.

Palabras-clave: Argumentación. Redacción. Bloques semánticos.

\section{Nota}

1 Depuis, à toutes les étapes de mon travail, je me suis posé la question - Suis-je fidèle à Saussure?. A bien des égards la répose était certes négative, mais pas en ce qui concerne la notion de valeur, que jai toujours voulu mettre au centre de mom travail en sémantique: chaque fois que je parlais dune entité, jai toujours tenté de la caractériser par la valeur permettant de la déclarer [...] (DUCROT, 2006, p.153). 


\section{Referências}

ANSCOMBRE, J.C. ; DUCROT, O. L'argumentation dans la langue. Bruxelles : Pierre Mardaga Éditeur, 1983.

BARBISAN, Leci. Uma proposta para o ensino da argumentação. In: Letras de Hoje, v.42, n. 2, p. 111-138. Porto Alegre: Edipucrs, 2007.

CAREL, Marion. L'entrelacement argumentatif. Lexique, discours et blocs sémantiques. Paris:Honoré Champion, 2011.

CAREL, Marion; DUCROT, Oswald. La semântica argumentativa: una introdución a la teoría de los Bloques Semánticos. Buenos Aires: Colihue, 2005.

CAREL, M.; DUCROT, O. Descrição argumentativa e descrição polifônica: o caso da negação. Letras de Hoje, Porto Alegre, v. 43, n. 1, p. 7-18, jan./mar. 2008.

DALL' CORTIVO-LEBLER, Cristiane; GOMES, Lauro. Argumentação e polifonia: ferramentas para o resgate dos sentidos da proposta de redação do Enem. Nonada: Letras em Revista. Porto Alegre, n. 28, v. 1, mai. 2017, pp. 262-280.

DUCROT, Oswald. O dizer e o dito. Campinas, SP: Pontes, 1987.

. Polifonia y argumentacion. Universidad del Valle, Calli, 1990.

. Os topoi na Teoria da Argumentação na Língua. Revista Brasileira de Letras. São Carlos. v. 1, n. 1, inverno, 1999.

DUCROT, Oswald. La Sémantique Argumentative peut-elle se réclamer de Saussure? In: SAUSSURE, Louis de (Org.). Nouveaux regards sur Saussure. Genebra: Librairie Droz, 2006.

DUCROT, Oswald. Argumentação retórica e argumentação linguística. Letras de Hoje, Porto Alegre, v. 44, n. 1, p. 20-25, jan./mar. 2009a.
DUCROT, Oswald. Prefácio. In: VOGT, Carlos. O intervalo semântico. Campinas: Ateliê Editorial, 2009b.

FIORIN, José Luiz (Org.). Introdução à Linguística. São Paulo: Contexto, 2015.

FLORES, Valdir do Nascimento; TEIXEIRA, Marlene. Introdução à Linguística da Enunciação. São Paulo: Contexto, 2013.

GRAEFF, Telisa Furlanetto. Teoria da argumentação na língua e compreensão de tema de redação. Revistado Programa de Pós-Graduação em Letras da Universidade de Passo Fundo, v. 1, n. 2, p. 114-126, jul./dez.2005.

GRAEFF, Telisa Furlanetto. A argumentação normativa e transgressiva em redações e seus Meios de expressão. Desenredo, Passo Fundo, v.2, n.2, p.188-202, jul./dez.2006.

SAUSSURE, Ferdinand de. Curso de Linguística Geral. São Paulo: Cultrix, 2002. 